\title{
Slug promotes hepatocellular cancer cell progression by increasing sox 2 and nanog expression
}

\author{
XIULAN ZHAO ${ }^{1,3^{*}}$, BAOCUN SUN ${ }^{1-3^{*}}$, DAN SUN $^{1 *}$, TIEJU LIU $^{1,3}, \mathrm{NA} \mathrm{CHE}^{1,3}$, \\ QIANG GU ${ }^{1,3}$, XUEYI DONG ${ }^{1}, \mathrm{RUI}_{\mathrm{LI}}{ }^{1}$, YANRONG LIU ${ }^{1}$ and $\mathrm{JING} \mathrm{LI}^{1}$ \\ ${ }^{1}$ Department of Pathology, Tianjin Medical University; ${ }^{2}$ Department of Pathology, Tianjin Cancer Hospital, \\ Tianjin Medical University, Tianjin 300060; ${ }^{3}$ Department of Pathology, Tianjin General Hospital, \\ Tianjin Medical University, Tianjin 300052, P.R. China
}

Received June 29, 2014; Accepted September 29, 2014

DOI: $10.3892 /$ or.2014.3562

\begin{abstract}
Transcription factor Slug plays an important role in the tumor invasion and metastasis of human hepatocellular carcinoma (HCC). This study aimed to explore the mechanism involved in the promotion of HCC progression by Slug. In the precent study, we demonstrated that Slug expression was significantly associated with metastasis and shorter survival time of HCC patients. Using ChIP-on-chip and microarray analysis, we identified the molecular profile of Slug downstream targets in HCC cells with Slug overexpression. The Wnt, Notch and Hedgehog pathways were identified to promote pluripotency maintaining overexpression factors sox 2 and nanog. Importantly, Slug showed a close relationship with sox 2 and nanog expression in HCC patients and in HCC xenografts in vivo. Notably, the DNA damaging reagent hydroxyurea had no effect on Slug, sox 2 and nanog expression in HCC cells with Slug overexpression; however knockdown of Slug by the short hairpin RNA approach markedly reduced sox 2 and nanog expression and inhibited HCC cell migration in vitro. The results of this study indicate that Slug promotes progression of HCC by promoting sox 2 and nanog overexpression. The related molecular pathways may be used as novel therapeutic targets for $\mathrm{HCC}$.
\end{abstract}

\section{Introduction}

Hepatocellular carcinoma (HCC) is the most common type of liver cancer and is the third leading cause of cancer-related deaths worldwide. Understanding the molecular biology and

Correspondence to: Professor Baocun Sun, Department of Pathology, Tianjin Cancer Hospital, Tianjin Medical University, Tianjin 300070 , P.R. China

E-mail: sunbaocun@aliyun.com; baocunsun@gmail.com

${ }^{*}$ Contributed equally

Key words: Slug, hepatocellular carcinoma, sox2, nanog exploring the mechanisms involved in progression of HCC may facilitate the development of new therapeutic strategies.

Recent studies have confirmed that the process of epithelial-mesenchymal transition (EMT) is an absolute requirement for tumor invasion and metastasis $(1,2)$. EMT may be regulated by a group of transcriptional factors $(3,4)$, and signaling pathways activated by intrinsic or extrinsic stimuli converge on these transcriptional factors and regulate the phenotypic changes of cancer cells (5). Developmental genetics research has identified many acting transcription factors that play crucial roles in embryogenesis by orchestrating EMT (6-9). In recent years, these embryonic transcription factors were found to have a close relationship with the malignant traits of cancer cells, such as motility, invasiveness, and resistance to apoptosis. Slug (SNAI2), a member of the Snail family of zinc-finger transcription factors, plays a crucial role in the regulation of EMT during embryogenesis $(10,11)$. Researchers have found that Slug is involved in cancer cell invasion, resistance to apoptosis and stem cell features (11-15).

To date, the mechanism involved in the promotion of HCC progression by Slag is currently unknown. Therefore, in the present study, we aimed to demonstrate the critical role of Slug in $\mathrm{HCC}$ progression and thus provide novel therapeutic strategies for HCC.

\section{Materials and methods}

Patient samples. HCC tissue specimens were obtained from 113 patients who underwent hepatectomy for HCC between 2001 and 2010 at the Tianjin Cancer Hospital, Tianjin Medical University. The diagnoses of the HCC samples were reviewed by senior pathologists. Detailed pathological and clinical data were collected.

Immunohistochemical methods. The immunohistochemical assay was performed as previously described (17-20).

Cell culture, stable cell lines and expression plasmids. As described in our previous study (21), human liver cancer cell lines (HepG2 and SMMC7221) were obtained from the American Type Culture Collection (ATCC, USA), and the Cell Bank of the Chinese Academy of Medical Sciences (Beijing, 
China). Transfection of HepG2 cells was performed with Lipofectamine 2000 reagent, and the clones were selected by G418. For the expression plasmids, full-length Slug complementary DNA (cDNA) was generated by normal human embryo total cDNA, and digested with XhoI/EcoRI and subcloned into pcDNA3.1 vectors. The resulting constructs were confirmed by DNA sequencing.

Retrovirus vectors and infections. For siRNA-mediated inhibition, the siRNA sequences against human Slug (5'-CAGACCCATTCTGATGTAAAG-3') were cloned into the psiHIV-nH1 lentiviral vector system (GeneCopoeia, FulenGen Co., Ltd., Guangzhou, China). Lentiviruses were produced by transient transfection of 293T cells with the plasmids, and lentiviral supernatants were collected $48 \mathrm{~h}$ post transfection and centrifuged at $500 \mathrm{x}$ g for $10 \mathrm{~min}$ to get rid of the cell debris. Following centrifugation, the supernatant was filtered through $0.45-\mu \mathrm{m}$ polyethersulfone low protein-binding filters. Then the virus suspension diluted in complete medium with Polybrene (Sigma-Aldrich, China) at a final concentration of $8 \mu \mathrm{g} / \mathrm{ml}$ was used to infect the target cells.

Western blot analysis. The whole cell lysates were resolved by way of sodium dodecyl sulfate-polyacrylamide gel electrophoresis and transferred onto polyvinylidene difluoride membranes (Millipore, Billerica, MA, USA). Blots were blocked and incubated with the primary antibody Slug (Cell Signaling Technology, Boston, MA, USA), CD133 (Santa Cruz Biotechnology, Inc., Dallas, TX, USA), sox2 (GeneTex, San Antonio, TX, USA), nanog (Novus Biologicals, Littleton, CO, USA), oct4, E-cadherin (both from Santa Cruz Biotechnology Inc.) and vimentin (Epitomics, Burlingame, CA, USA) followed by incubation with a secondary antibody (Santa Cruz Biotechnology, Inc.). Blots were developed using an enhanced chemiluminescence detection kit (Amersham Pharmacia Biotech, Piscataway, NJ, USA). For protein loading analyses, a monoclonal $\beta$-actin antibody (Santa Cruz Biotechnology, Inc.) was used.

Apoptosis measurements. The cells were pelleted by centrifugation and resuspended for apoptosis analysis using the FITC-Annexin V and PI detection kit (Sigma-Aldrich) according to the manufacturer's instructions.

ChIP-on-chip analysis (GEO accession number: GSE41028). Samples were harvested from three groups (HepG2-control cells in regular culture, HepG2-Slug cells in regular culture and HepG2-Slug cells on Matrigel) and sent to CapitalBio Corporation (Beijing, China) for further analysis.

Cells $\left(1 \times 10^{8}\right)$ were fixed with $1 \%$ formaldehyde in culture medium for $10 \mathrm{~min}$ at room temperature followed by quenching with $0.125 \mathrm{M}$ glycine for $5 \mathrm{~min}$. The cells were washed twice with ice-cold PBS and washed in $10 \mathrm{ml}$ of lysis buffer $(10 \mathrm{mM}$ Tris- $\mathrm{HCl} \mathrm{pH} 7.5,10 \mathrm{mM} \mathrm{NaCl}, 3 \mathrm{mM} \mathrm{MgCl}_{2}, 0.5 \%$ IGEPAL, $1 \mathrm{mM}$ PMSF) three times at $4^{\circ} \mathrm{C}$. The crosslinked chromatin was sheared to an average size of 500 bp by ten $30-$ sec pulses using a sonicator. The chromatin solution was then incubated overnight with an anti-Slug antibody at $4^{\circ} \mathrm{C}$. After incubation with protein $\mathrm{A}$ beads for $2 \mathrm{~h}$ at $4^{\circ} \mathrm{C}$, the immune complexes were collected by centrifugation and washed with the following buffers each for $10 \mathrm{~min}$ at $4^{\circ} \mathrm{C}$ : RIPA buffer $(150 \mathrm{mM} \mathrm{NaCl}$, $50 \mathrm{mM}$ Tris $\mathrm{pH} 8.0,0.1 \%$ SDS), high-salt buffer $(500 \mathrm{mM}$ $\mathrm{NaCl}, 50 \mathrm{mM}$ Tris pH 8.0, 0.1\% SDS, 1\% NP-40), LiCl buffer (250 mM LiCl, $50 \mathrm{mM}$ Tris $\mathrm{pH} 8.0,0.5 \% \mathrm{Na}$ deoxycholate, $1 \%$ NP-40) and 2X TE (20 mM Tris pH 8.0, 2 mM EDTA). The protein-DNA complexes were eluted from the beads in $450 \mu$ l elution buffer $\left(1 \%\right.$ SDS, $\left.100 \mathrm{mM} \mathrm{NaHCO}_{3}\right)$ at $55^{\circ} \mathrm{C}$ for $2 \mathrm{~h}$ followed by the addition of proteinase $\mathrm{K}$ to $500 \mu \mathrm{g} / \mathrm{ml}$ and overnight incubation at $65^{\circ} \mathrm{C}$. Genomic DNA was isolated from the precipitated material as well as from the sheared chromatin input (1/100 of the material used for ChIP) by phenol extraction and ethanol precipitation. One microgram ChIP DNA was directly labeled by DSL technology at CapitalBio Corporation. The labeled ChIP DNA was precipitated with 0.1 volume $5 \mathrm{M}$ $\mathrm{NaCl}$ and 1 volume isopropanol, and hybridized in $80 \mu \mathrm{l}$ of hybridization buffer (3X SSC, $0.2 \%$ SDS, 5X Denhart's, 25\% formamide). Arrays were hybridized in CapitalBio hybridization stations for $16-18 \mathrm{~h}$ at $42^{\circ} \mathrm{C}$, and then washed at $42^{\circ} \mathrm{C}$ in $0.2 \% \mathrm{SDS} / 0.2 \mathrm{X} \mathrm{SSC}$, at room temperature in $0.2 \mathrm{X} \mathrm{SSC}$, and in $0.05 X$ SSC. Data of arrays were analyzed by the technicians at CapitalBio Corporation.

Microarray analysis (GEO accession number: GSE41028). Total RNA was extracted from three samples (HepG2-control cells in regular culture, HepG2-Slug cells in regular culture and HepG2-Slug cells on Matrigel) using TRIzol (Invitrogen Life Technologies, Carlsbad, CA, USA) following the manufacturer's instructions. Three samples of total RNA were sent to CapitalBio Corporation for microarray analysis.

Sulforhodamine B (SRB) assay. HepG2 and HepG2-Slug cells were cultured in a 96-well plate at a concentration of $10^{4} / 100 \mu 1$. Hydroxyurea (Sigma-Aldrich) was used to induce DNA damage (final concentration, $2 \mathrm{mM}$ ). The cells were treated with $10 \%$ trichloroacetic acid for $5 \mathrm{~min}$ after $48 \mathrm{~h}$, and then stained by sulforhodamine B for $30 \mathrm{~min}$ at $37^{\circ} \mathrm{C}$. A microplate reader (BioTek, Winooski, VT, USA) was used to measure the absorbance value at $490 \mathrm{~nm}$.

Xenografts. Male BALB/c nude mice, 5 weeks of age, were purchased from Beijing, China. Viable cells $\left(5 \times 10^{6}\right)$ were injected under the skin of 20 nude mice with a 26 -gauge needle. The nude mice with xenografts were monitored for 28 days before sacrifice.

Ethics statement. Human HCC tissue collection and analysis in this study were approved by the Ethics Committee of Tianjin Medical University, China. All animal research was approved by the Animal Ethics Committee of Tianjin Medical University, China.

Availability of supporting data section. The microarray data has been deposited in NCBI. The following is the link (http://www.ncbi.nlm.nih.gov/projects/geo/query/acc. cgi?acc=GSE41028).

\section{Results}

Expression of Slug is correlation with metastasis and shorter survival time in HCC patients. Slug expression in 113 cases 

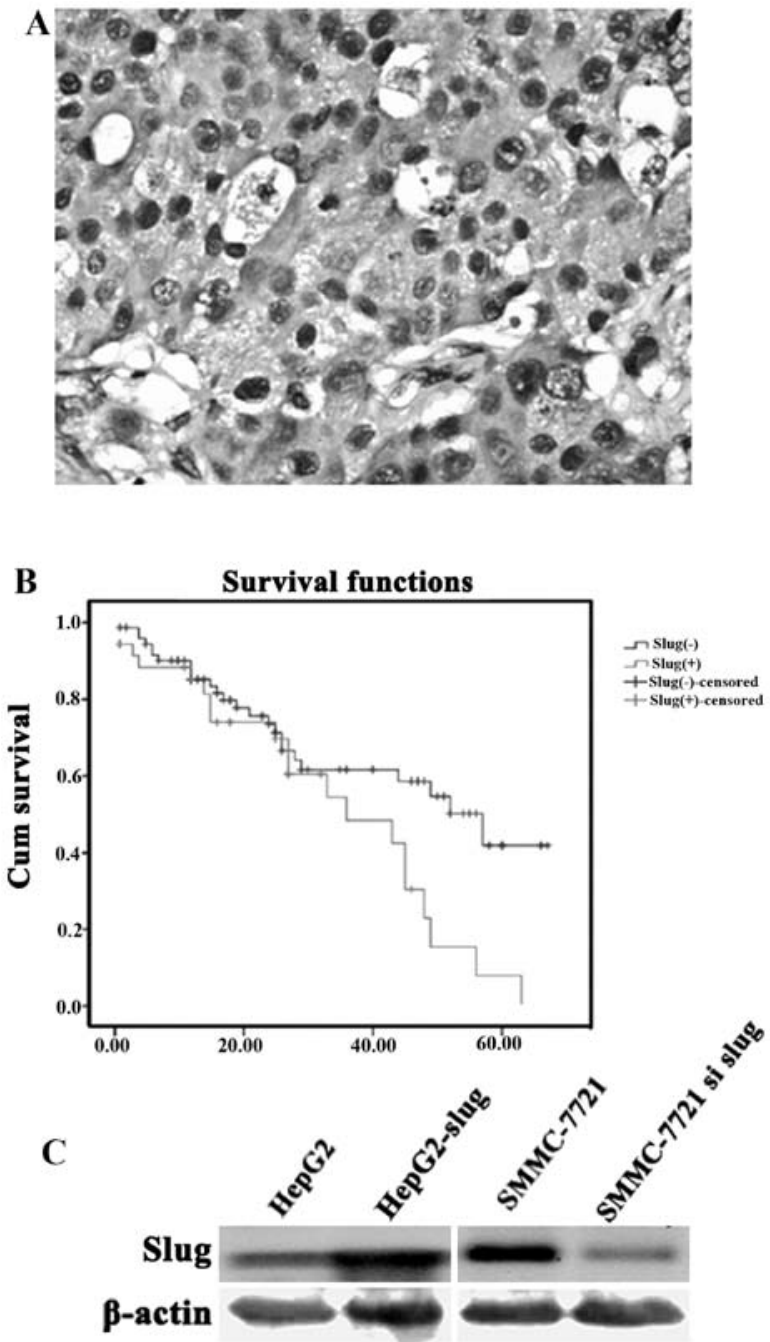

Figure 1. (A) Positive Slug expression in hepatocellular carcinoma (HCC) specimen. (B) Expression of Slug was associated with shorter survival time in the HCC patients. (C) Slug showed different expression in HepG2 and SMMC 7721 cells.

of primary HCC was examined by IHC. Slug expression was identified in the cytoplasm as well as in the nucleus of the cancer cells (Fig. 1A). Cases with a percentage of positive cells $\geq 10 \%$ were considered as Slug-positive. Correlations between Slug expression and clinicopathological characteristics of the patients are shown in Table I. Among all factors compared, the metastasis status was significantly different between the Slug-positive group and the Slug-negative group $(\mathrm{P}=0.020)$. The positive rate of Slug was $46.8 \%$ in the metastasis group, higher than that of the nonmetastasis group (25.8\%).

Survival analysis indicated that patients with Slug positive expression in HCC tissue were significantly associated with poor overall survival (Fig. 1B). The mean (95\% CI) overall survival time was 34.311 (27.084-41.538) and 44.721 (38.19251.251) months respectively for patients with and without Slug positive expression in $\mathrm{HCC}$ tissue $(\mathrm{P}=0.025)$.

Molecular profiling of Slug downstream targets in HCC cells cultured on Matrigel. Slug expression was not similarly expressed in the different HCC cell lines as detected by western blotting. We found that there was a lower level of Slug
Table I. Correlation between Slug expression and clinicopathological characteristics of the patients with hepatocellular carcinoma.

\begin{tabular}{lccc}
\hline & \multicolumn{2}{c}{ Slug expression } & \\
\cline { 2 - 3 } $\begin{array}{l}\text { Clinicopathological } \\
\text { parameters }\end{array}$ & $\begin{array}{c}\text { Positive } \\
(\mathrm{n}=39)\end{array}$ & $\begin{array}{c}\text { Negative } \\
(\mathrm{n}=74)\end{array}$ & P-value \\
\hline Age (years) & $54.6 \pm 1.6$ & $53.5 \pm 1.4$ & 0.603 \\
Gender & & & 0.445 \\
Male & 31 & 63 & \\
Female & 8 & 11 & \\
Differentiation grade & & & 0.246 \\
I/II & 11 & 29 & \\
III/IV & 28 & 45 & 0.508 \\
Stage & & & \\
I/II & 18 & 39 & \\
III/IV & 21 & 35 & \\
Metastasis & & & \\
Yes & 22 & 25 & \\
No & 17 & 49 & \\
\hline
\end{tabular}

expression in the HepG2 cells compared with the SMMC-7721 cells which showed a higher level (Fig. 1C).

HepG2 cells were then transfected with Slug cDNA and showed an increased Slug protein expression (Fig. 1C). Matrigel induces cells to migrate, and this migratory behavior can be referred to as a model of tumor cell metastasis in vitro. Thus, we cultured HepG2 and HepG2-Slug cells on Matrigel in order to delineate the Slug downstream targets during HCC cell migration. On Matrigel, HepG2-Slug cells showed a more aggressive behavior by forming tubular structure, suggesting that Slug has the potential to promote cell migration in vitro.

Slug acts as a transcriptional repressor that binds to E-box motifs, and the binding site of Slug is known as E-box (5'-CANNTG-3') (16). Next, we examined the promoters that bind to Slug using combined ChIP and Affymetrix Gene Chip (ChIP-on-chip) for HepG2-control cells in regular culture (HCR), HepG2-Slug cells in regular culture (HSR) and HepG2-Slug cells on Matrigel (HSM). The results showed that the number of gene promoters that bound to Slug only increased to 28 in the HSR vs. HCR; however, on Matrigel, the number of gene promoters that bound to Slug in HSM increased significantly and the increased promoter number reached 150 for HSM vs. HSR, and 237 for HSM vs. HCR (Fig. 2A). Our study demonstrated that the peak binding of the promoter by Slug occurred in HepG2-Slug cells on Matrigel.

Roche NimbleGen microarray analysis was employed to assess global genome expression in the HCR, HSR and HSM. Our analysis identified 2,873 genes that were differentially expressed for HSR vs. HCR; however, there were 6,023 and 8018 genes that were differentially expressed for HSM vs. HSR and HSM vs. HCR (Fig. 2B and C). The results suggest that during the process of HCC cell migration when cells were cultured on Matrigel such as HSM, Slug could bind more genes 
A

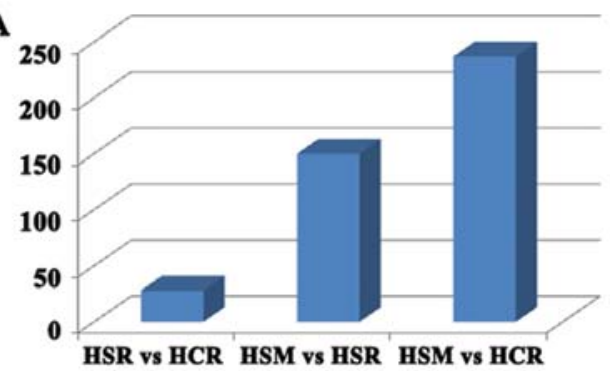

C

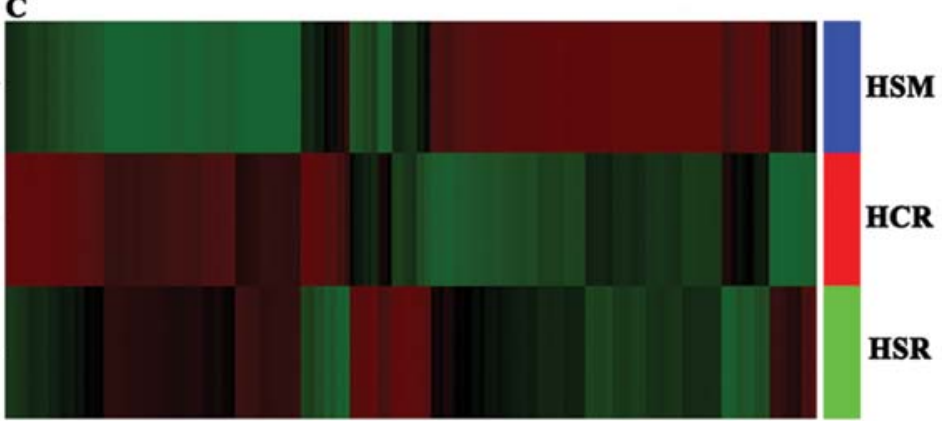

$B_{450}$

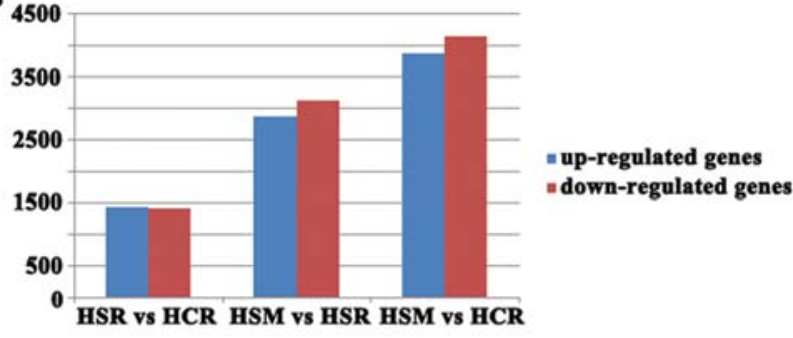

D

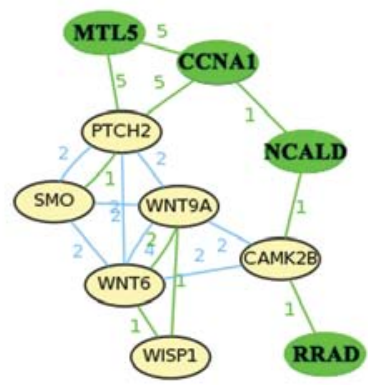

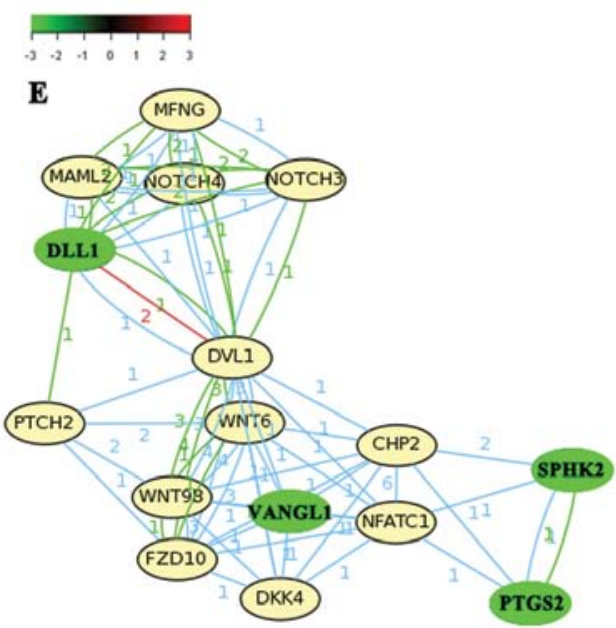

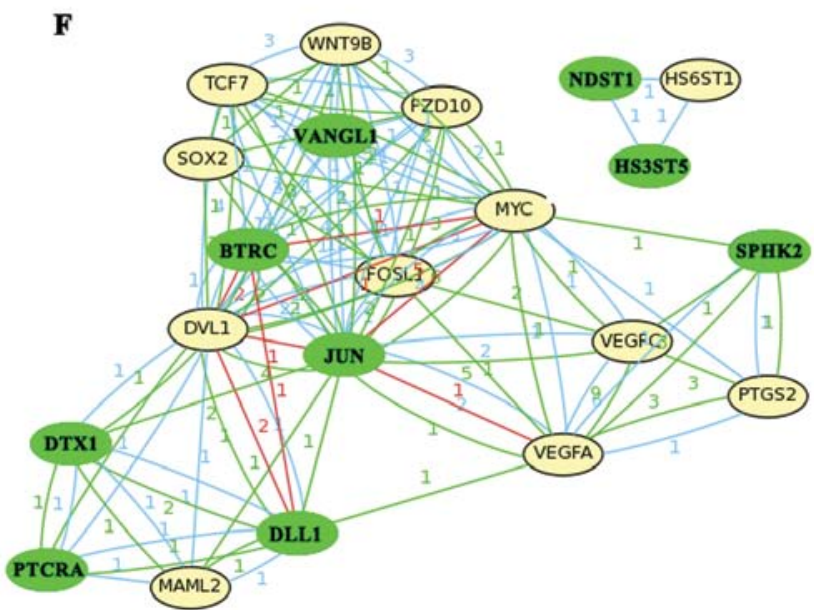

Figure 2. Molecular profiling of Slug downstream targets in hepatocellular carcinoma (HCC) cells. (A) In a 3D Matrigel condition, the number of gene promoters that bound to Slug in HepG2-Slug cells on Matrigel (HSM) increased significantly. (B and C) Our analysis identified 2,873 genes that were differentially expressed between HepG2-Slug cells in regular culture (HSR) vs. HepG2-control cells in regular culture (HCR); however, there were 6,023 and 8,018 genes that were differentially expressed for HSM vs. HSR and HSM vs. HC. (D) The Wnt and Hedgehog pathways were identified in HSR vs. HCR. The genes labeled by a green color were those containing E-box and downregulated by Slug. (E and F) The Wnt, Notch, Hedgehog and VEGF pathways were identified in (E) HSM vs. HSR and (F) HSM vs. HCR. The genes labeled by a green color were those containing E-box and downregulated by Slug.

and provoked more genes to be upregulated or downregulated thus contributing to HCC progression.

By Molecule Annotation System (MAS) analysis, many pathways were identified in HSR vs. HCR, HSM vs. HSR as well as HSM vs. HCR, such as ECM-receptor interaction pathway, systemic lupus erythematosus pathway and focal adhesion pathway. Since our results showed that Slug expression contributed to HCC progression, we identified the cancer-related pathway as the major signaling pathway. Between HSR vs. HCR, the involved pathways were Wnt and Hedgehog pathways initiated by Slug downregulated genes containing E-boxes (MTL5, RRAD, NCALD and CCNA1). The downregulation of MTL5, RRAD, NCALD and CCNA1 activated genes of the Wnt and Hedgehog pathways (WNT9A, WNT6, CAMK2B, WISP1, SMO and PTCH2) (Fig. 2D).
Similarly, the Wnt, Notch and Hedgehog pathways and the VEGF pathway were identified as major pathways in HSM vs.HSR and in HSMvs.HCR (Fig.2EandF). Furthermore, more genes were involved in HSM compared with HSR and HCR, suggesting that Wnt, Notch and Hedgehog pathway genes promoted by Slug overexpression play an important role in the process of cancer cell invasion. Importantly, the activation of the Wnt and Notch pathways promoted sox 2 expression by microarray analysis and the upregulation was evident in HSM. Further western blotting validated the elevated sox 2 and nanog expression present in HSM (Fig. 3). Our study suggests that the reprogramming factors sox 2 and nanog contribute to tumor progression in HCC. In addition, the VEGF pathway was also activated in HSM, which may be induced by SPHK2 downregulation initiated by Slug (Fig. 2E and F). 


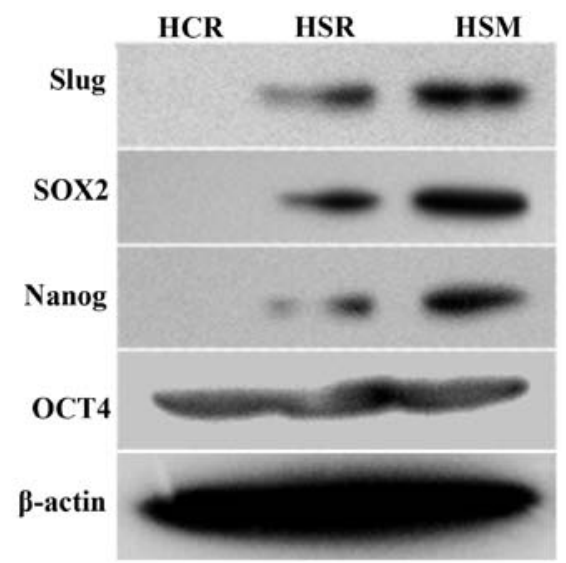

Figure 3. Western blotting revealed elevated sox 2 and nanog expression present in HepG2-Slug cells on Matrigel (HSM) while oct4 expression did not show differences among HSM, HepG2-Slug cells in regular culture (HSR) and HepG2-control cells in regular culture (HCR).

Slug overexpression has a close relationship with increased sox 2 and nanog expression in HCC patients. The expression of pluripotency maintaining factors (sox 2 , nanog, oct 4 ) which are involved in specification and maintenance of cancer stem cells were examined by immunohistochemistry in HCC specimen. Positive cells were indicated by the presence of brown staining in the nucleus (Fig. 4A and B). The percentage of positive cells $\geq 10 \%$ was considered as positive. Sox 2 and Nanog were detected in 29.2 and $13.3 \%$ of hepatocellular cancer tissues; whereas there was lack of Oct 4 expression in all the $113 \mathrm{HCC}$ cases (Fig. 4C). Importantly, there was a significant correlation between Slug and sox 2 expression $(\mathrm{r}=0.230, \mathrm{P}=0.014)$ as well as Slug and nanog expression $(\mathrm{r}=0.210, \mathrm{P}=0.026)$.

Slug silencing induces apoptosis and inhibits cell migration in HCC cells in vitro. HepG2-Slug and HepG2-control cells were treated with 2-10 $\mathrm{mM}$ hydroxyurea (HU) for $48 \mathrm{~h}$ and were then assessed for cell proliferation employing the SRB assay. Cell proliferation in the HepG2-control cells was significantly inhibited by HU to different extents depending on the dose. However, HepG2-Slug cells showed increased resistance to the cytotoxic effects of HU compared to the cultured HepG2control cells. Cell proliferation in the HepG2-Slug cells was inhibited to a lesser extent and the inhibition was independent of the dose (Fig. 5A).

To evaluate whether endogenous Slug plays any role in HCC cells with high Slug expression, we knocked down Slug expression in SMMC-7721 cells using Slug siRNA. The concomitant decrease in the Slug protein level in the Slug siRNA-treated cells was evident from the western blot data (Fig. 1C). Since Slug overexpression conferred more resistance to $\mathrm{HU}$, we next observed whether or not HU treatment had an effect on Slug expression. HepG2-control, HepG2-Slug, SMMC-7721-control and SMMC-7721-siRNASlug cells were treated with $2 \mathrm{mM} \mathrm{HU}$ for $48 \mathrm{~h}$ and western blotting showed that the expression level of Slug was not reduced by HU in the HepG2-Slug and SMMC-7721 cells with higher Slug expression (Fig. 5B). In addition, western blot analysis demonstrated the maintenance of mesenchymal marker vimentin expression and the $\mathrm{CD}_{133}{ }^{+} \mathrm{CSC}$ phenotype when HepG2-Slug and
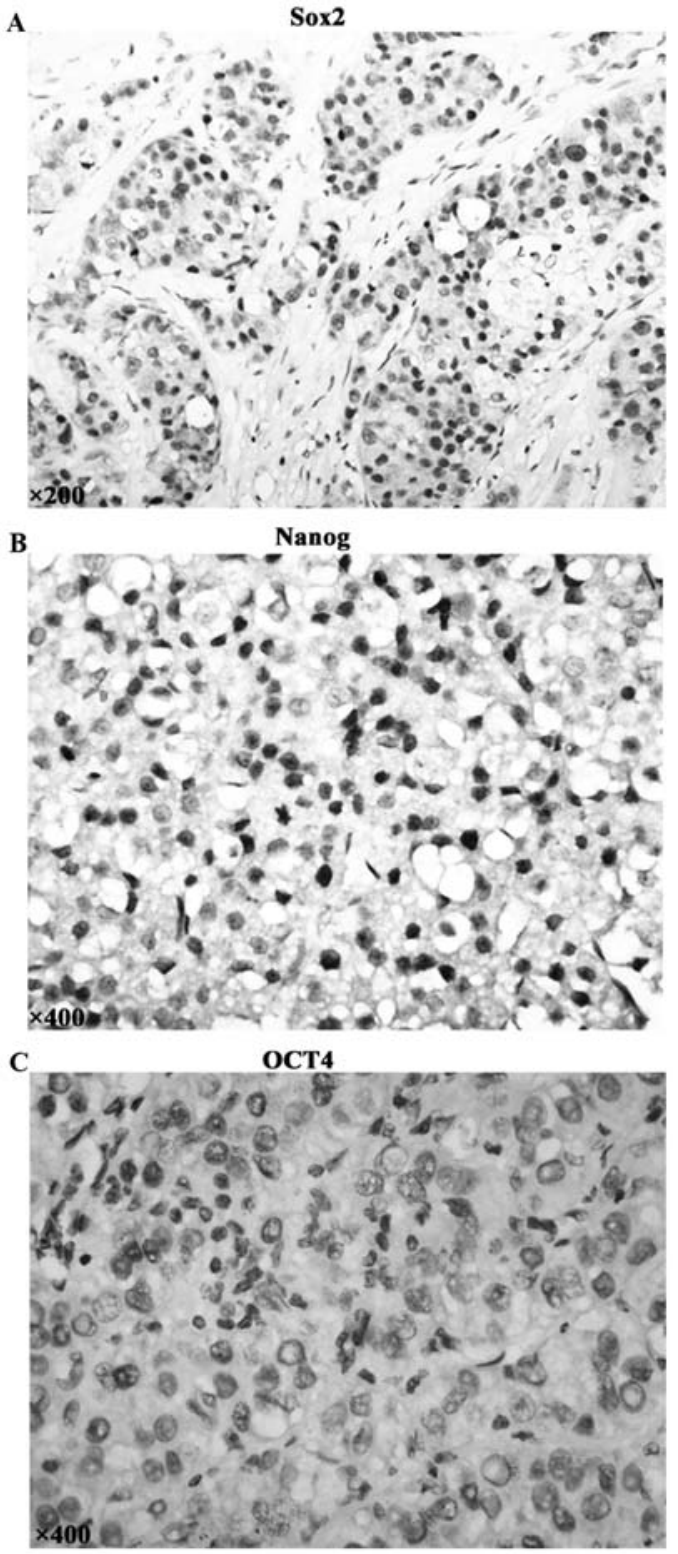

Figure 4. (A) Sox 2 positive expression was detected in the nucleus in hepatocellular carcinoma (HCC) samples. (B) Nanog positive expression was detected in the nucleus in HCC sample. (C) There was lack of Oct4 expression in all the HCC cases.

SMMC-7721 cells were treated with HU. Importantly, neither sox 2 nor nanog expression was reduced by HU treatment (Fig. 5B). Additionally, cell migration was not inhibited when HepG2-Slug and SMMC-7721 cells were treated with HU (Fig. 5C).

Analysis of Annexin $\mathrm{V}^{+}$cells showed that the fraction of Annexin $\mathrm{V}^{+}$cells in the HepG2-Slug and SMMC-7721 cells with high Slug expression did not increase significantly when exposed to HU compared with the control cells. However, SMMC-7721 cells depleted of Slug, similar to the HepG2 cells with low Slug expression treated with HU, showed a significant increase in the proportion of Annexin $\mathrm{V}^{+}$cells (Fig. 5D). Therefore Slug silencing played a major role in the commitment to apoptosis. Moreover, SMMC-7721 cells with Slug silencing showed reduced mesenchymal marker vimentin expression and the CD133 non-CSC phenotype (Fig. 5B). 
$\mathbf{A}$

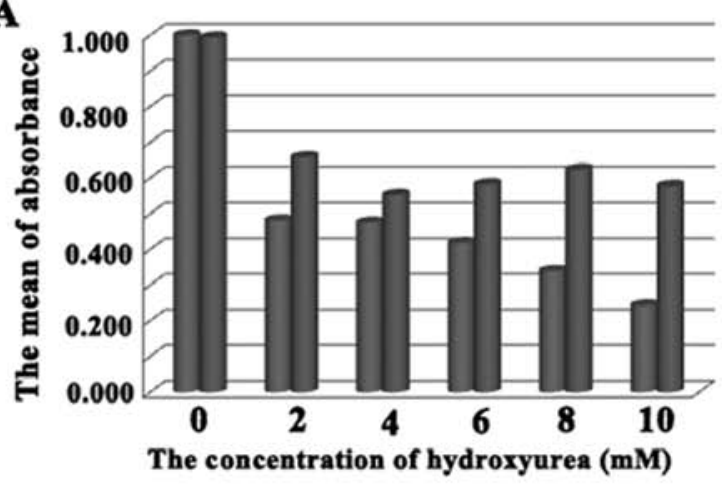

B

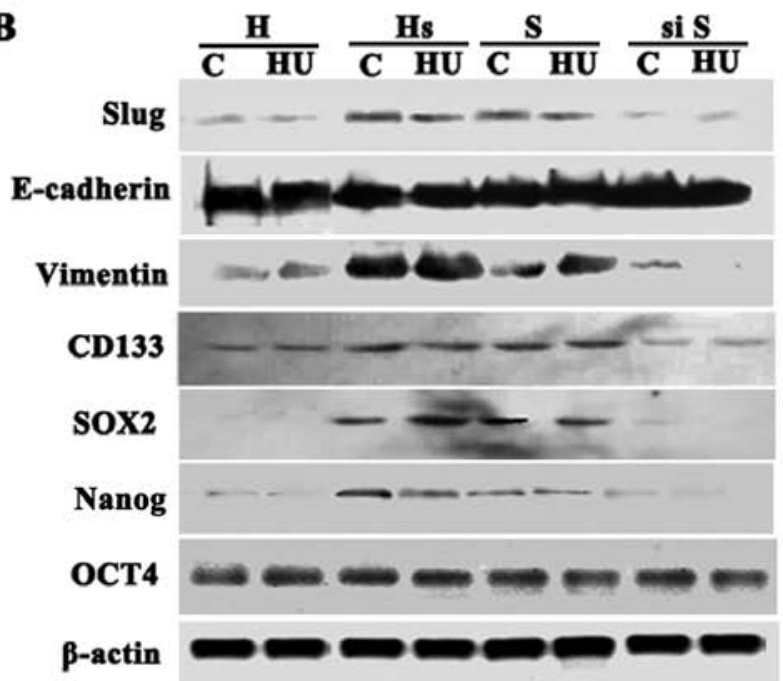

C
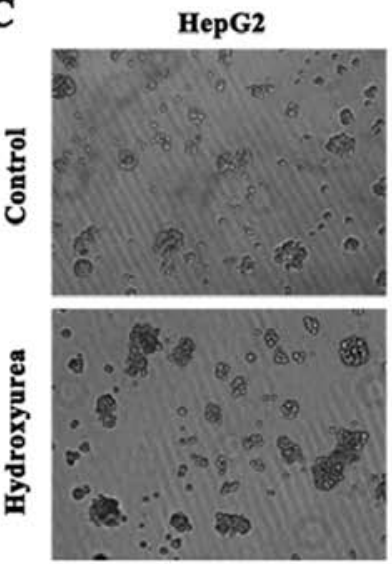

HepG2-Slug
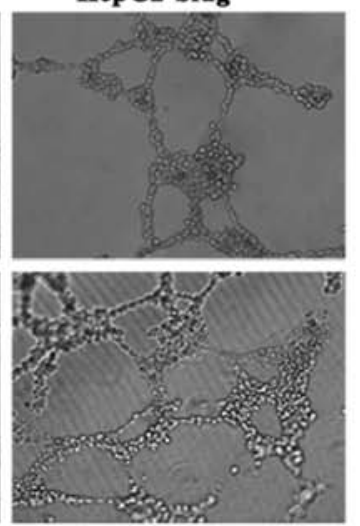

D
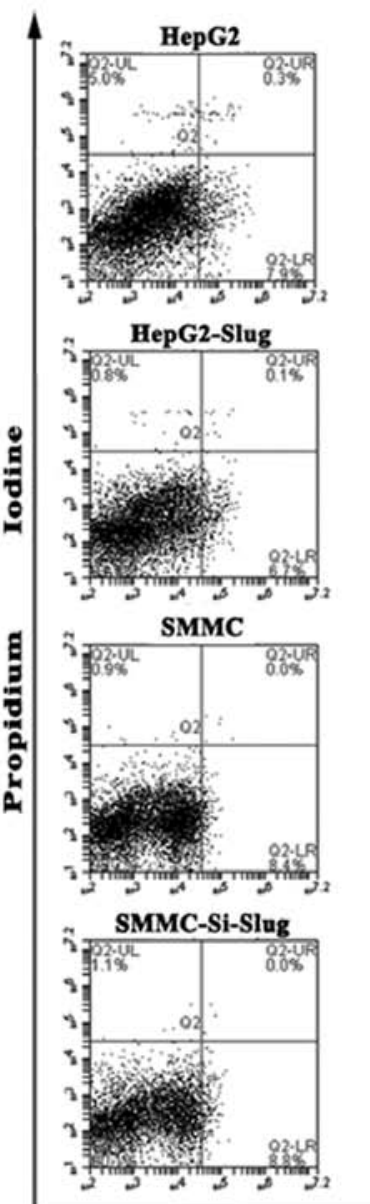

Annexin $V$ staining

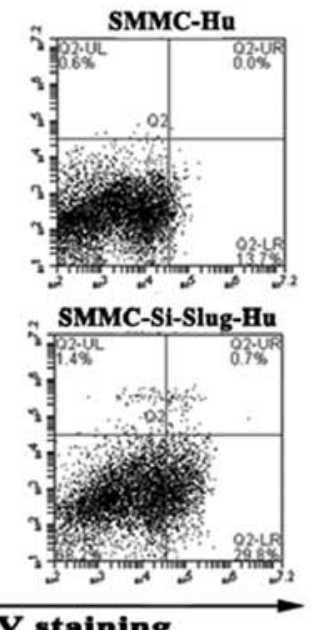

C-Si-Slug-Hu

si SMMC
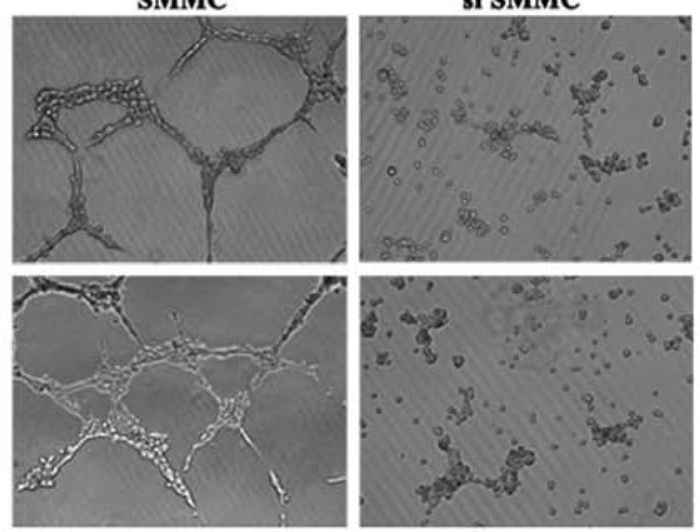

Figure 5. Slug silencing induces apoptosis and inhibits cell migration in hepatocellular carcinoma (HCC) cells. (A) Cell proliferation in HepG2-Slug cells (Hs) was inhibited to a lesser extent when compared to HepG2-control cells $(\mathrm{H})$ and the inhibition was independent of the dose. (B) Decreased expression of Slug protein in the Slug siRNA-treated SMMC-7721 cells (si S) was evident from the western blot data. HepG2-control (H), HepG2-Slug (Hs), SMMC-7721-control (S) and SMMC-7721-siRNASlug cells (si S) were treated with $2 \mathrm{mM}$ hydroxyurea (HU) for $48 \mathrm{~h}$ and western blotting showed that the expression level of Slug was not reduced by HU in the HepG2 Slug cells and SMMC-7721 cells with high Slug expression. Vimentin expression and the CD133 ${ }^{+}$CSC phenotype were maintained when HepG2-Slug and SMMC-7721 cells were treated with HU. In addition, neither sox2 nor nanog expression was reduced by HU treatment. Remarkably, SMMC-7721 cells with Slug silencing showed reduced mesenchymal marker vimentin expression, and the CD133 non-CSC phenotype. Although oct 4 expression was not reduced by Slug silencing, sox 2 and nanog expression was decreased obviously. (C) Inhibition of cell migration was noted in the SMMC-7721 cells with Slug silencing (si SMMC) compared with HepG2-Slug and SMMC-7721 cells (SMMC) treated with HU or without. (D) Analysis of Annexin $\mathrm{V}^{+}$cells showed that the fraction of Annexin $\mathrm{V}^{+}$cells in the HepG2-Slug and SMMC-7721 with high Slug expression did not increase significantly when exposed to HU compared with control cells. However, SMMC-7721 cells depleted of Slug, similar to HepG2 cells with low Slug expression treated with $\mathrm{HU}$, showed a significant increase in the level of Annexin $\mathrm{V}^{+}$cells.

Remarkably, Slug silencing inhibited SMMC-7721 cell migration on Matrigel with or without HU treatment (Fig. 5C).
Slug silencing inhibits sox 2 and nanog expression in vivo. To further confirm the relationship of Slug with HCC progression 

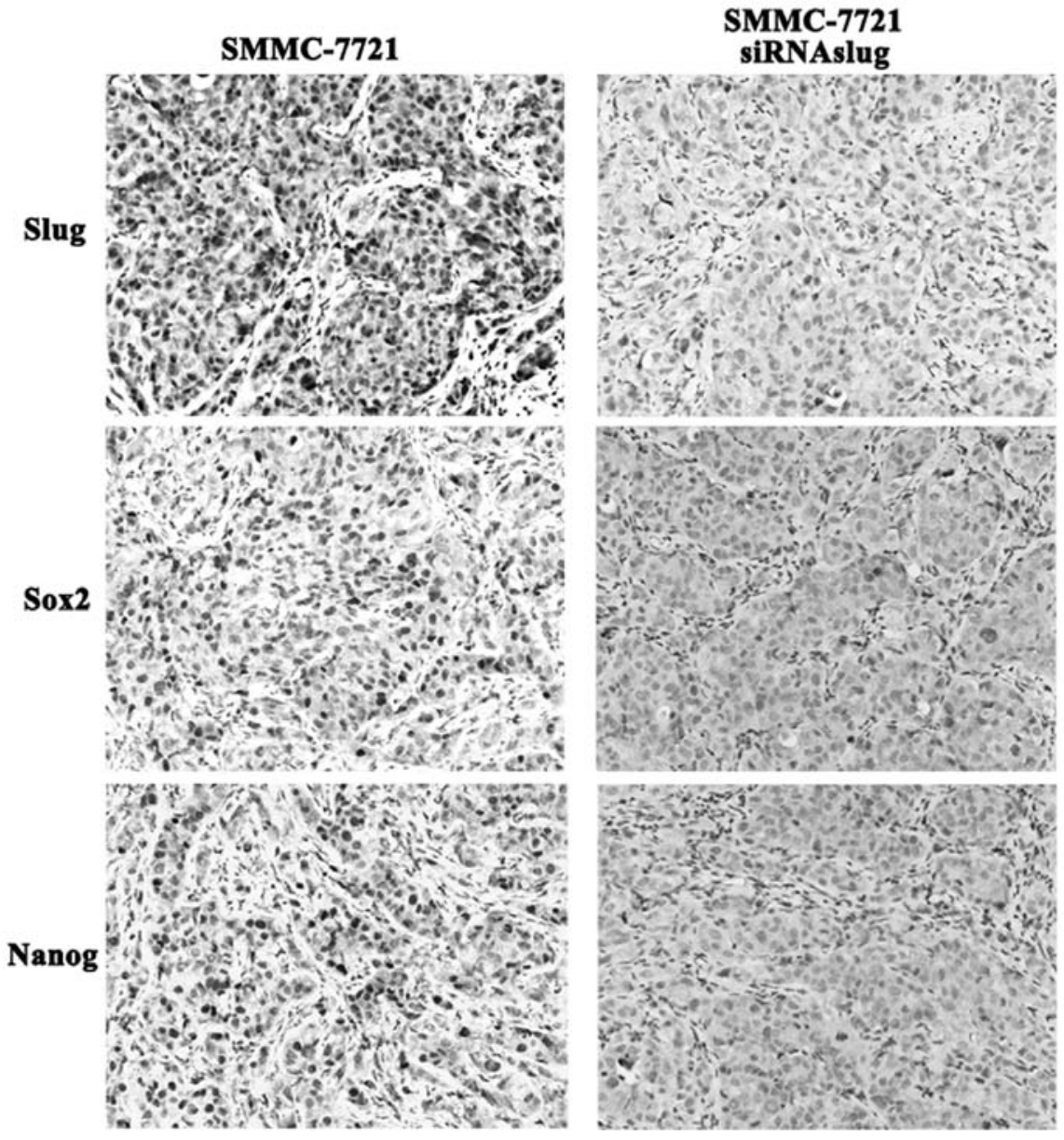

Figure 6. Slug silencing inhibits sox 2 and nanog expression in vivo.

in vivo, a xenograft model of human $\mathrm{HCC}$ progression employing SMMC-7721 cells and SMMC-7721-siRNASlug cells was established. Although neither SMMC-7721 nor SMMC-7721siRNASlug xenografts displayed propensity to metastasize to distant organs such as liver and lung, the SMMC-7721siRNASlug cells failed to grow vigorously in the nude mice as compared to the parental SMMC-7721 cells. Remarkably, after in vivo growth, SMMC-7721-siRNASlug xenografts displayed lower sox 2 and nanog expression while higher levels were noted in the SMMC-7721 xenografts (Fig. 6), suggesting that Slug has a close relationship with sox 2 and nanog expression.

\section{Discussion}

Although the specific role of Slug in the downregulation of E-cadherin is not completely clear, Slug is critical to induce the EMT phenotype, cancer stem-like properties and mediate radioresistance and chemoresistance (22-25). In the present study, we detected Slug expression in 113 cases of HCC tissue samples to characterize the linkage between the activation of Slug and metastasis. Statistical analysis showed that expression of Slug was correlated with metastasis and a shorter survival time in HCC patients. Therefore, our study suggests that Slug overexpression could serve as a poor prognosis marker.

ChIP-on-chip analysis showed that the greatest number of binding peaks of Slug occurred in the HepG2-Slug cells on Matrigel. We also identified the novel non-canonical pathway,
Wnt and Notch pathway, leading to sox 2 and nanog overexpression in vitro. Recent research showed that Sox2, Nanog and Oct4, can directly reprogram somatic cells to a pluripotent stem cell state (26-29). In our study, HCC progression may be induced through the activation of a reprogramming-like mechanism promoted by Sox 2 and nanog.

Our data also showed that a correlation between expression levels of Slug and increased sox 2 and nanog expression was obvious in the human HCC tissue specimens and HCC xenografts in vivo, thus indicating that Slug is sufficient to induce sox 2 and nanog overexpression. Interestingly, Slug overexpression potentiated the chemoresistance properties of HepG2 cells to DNA damage reagent HU. Moreover, HU treatment could not affect EMT, the CSC phenotype and cell migration in HCC cells with Slug overexpression. Notably, our study showed that Slug silencing inhibited cell migration on Matrigel in vitro, suggesting that Slug plays a crucial role in HCC progression.

In conclusion, our findings reveal a previously unidentified role of Slug to promote HCC progression by activation of reprogramming-related genes sox 2 and nanog.

\section{Acknowledgements}

This study was partly supported by a grant from the Key Project of the National Natural Science Foundation of China (no. 81230050), the National Natural Science Foundation of 
China (nos. 81172046 and 81173091), the Key Project of the Tianjin Natural Science Foundation (no. 12JCZDJC23600) and the Tianjin Natural Science Foundation (no. 12JCYBJC15500).

\section{References}

1. Książkiewicz M, Markiewicz A and Zaczek AJ: Epithelialmesenchymal transition: a hallmark in metastasis formation linking circulating tumor cells and cancer stem cells. Pathobiology 79: 195-208, 2012.

2. Tiwari N, Gheldof A, Tatari M and Christofori G: EMT as the ultimate survival mechanism of cancer cells. Semin Cancer Biol 22: 194-207, 2012.

3. Sánchez-Tilló E, Liu Y, de Barrios O, Siles L, Fanlo L, Cuatrecasas M, Darling DS, Dean DC, Castells A and Postigo A: EMT-activating transcription factors in cancer: beyond EMT and tumor invasiveness. Cell Mol Life Sci 69: 3429-3456, 2012.

4. Balli D, Ustiyan V, Zhang Y, Wang IC, Masino AJ, Ren X Whitsett JA, Kalinichenko VV and Kalin TV: Foxm1 transcription factor is required for lung fibrosis and epithelial-tomesenchymal transition. EMBO J 32: 231-244, 2013.

5. Craene BD and Berx G: Regulatory networks defining EMT during cancer initiation and progression. Nat Rev Cancer 13 97-110, 2013

6. Wehbe M, Soudja SM, Mas A, Chasson L, Guinamard R, de Tenbossche CP, Verdeil G, Van den Eynde B and SchmittVerhulst AM: Epithelial-mesenchymal-transition-like and TGF $\beta$ pathways associated with autochthonous inflammatory melanoma development in mice. PLoS One 7: e49419, 2012.

7. Suh Y, Yoon CH, Kim RK, Lim EJ, Oh YS, Hwang SG, An S, Yoon G, Gye MC, Yi JM, Kim MJ and Lee SJ: Claudin-1 induces epithelial-mesenchymal transition through activation of the c-Abl-ERK signaling pathway in human liver cells. Oncogene 32: 4873-4882, 2013.

8. Tanaka Y, Terai Y, Kawaguchi H, Fujiwara S, Yoo S, Tsunetoh S, Takai M, Kanemura M, Tanabe A and Ohmichi M: Prognostic impact of EMT (epithelial-mesenchymal-transition)-related protein expression in endometrial cancer. Cancer Biol Ther 14 13-19, 2013.

9. Zheng X, Vittar NB, Gai X, Fernandez-Barrena MG, Moser CD, Hu C, Almada LL, McCleary-Wheeler AL, Elsawa SF, Vrabel AM, Shire AM, Comba A, Thorgeirsson SS, Kim Y, Liu Q, Fernandez-Zapico ME and Roberts LR: The transcription factor GLI1 mediates TGF $\beta 1$ driven EMT in hepatocellular carcinoma via a SNAI1-dependent mechanism. PLoS One 7: e49581, 2012.

10. Kim NH, Kim HS, Li XY, Lee I, Choi HS, Kang SE, Cha SY, Ryu JK, Yoon D, Fearon ER, Rowe RG, Lee S, Maher CA, Weiss SJ and Yook JI: A p53/miRNA-34 axis regulates Snail1dependent cancer cell epithelial-mesenchymal transition. J Cell Biol 195: 417-433, 2011.

11. Mathsyaraja $\mathrm{H}$ and Ostrowski MC: Setting Snail2's pace during EMT. Nat Cell Biol 14: 1122-1123, 2012.

12. Smith BN and Odero-Marah VA: The role of Snail in prostate cancer. Cell Adh Migr 6: 433-441, 2012.

13. Shimokawa M, Haraguchi M, Kobayashi W, Higashi Y, Matsushita S, Kawai K, Kanekura T and Ozawa M: The transcription factor Snail expressed in cutaneous squamous cell carcinoma induces epithelial-mesenchymal transition and down-regulates COX-2. Biochem Biophys Res Commun 430: 1078-1082, 2013.

14. Kume K, Haraguchi M, Hijioka H, Ishida T, Miyawaki A, Nakamura $\mathrm{N}$ and Ozawa M: The transcription factor Snail enhanced the degradation of E-cadherin and desmoglein 2 in oral squamous cell carcinoma cells. Biochem Biophys Res Commun 430: 889-894, 2013.
15. Lemma S, Karihtala P, Haapasaari KM, Jantunen E, Soini Y, Bloigu R, Pasanen AK, Turpeenniemi-Hujanen $\mathrm{T}$ and Kuittinen O: Biological roles and prognostic values of the epithelial-mesenchymal transition-mediating transcription factors Twist, ZEB1 and Slug in diffuse large B-cell lymphoma. Histopathology 62: 326-333, 2013.

16. Bhat-Nakshatri P, Appaiah H, Ballas C, Pick-Franke P, Goulet R Jr, Badve S, Srour EF and Nakshatri H: SLUG/SNAI2 and tumor necrosis factor generate breast cells with CD $44^{+} / \mathrm{CD} 24$ phenotype. BMC Cancer 10: 411, 2010.

17. Sun T, Sun BC, Zhao XL, Zhao N, Dong XY, Che N, Yao Z, Ma YM, Gu Q, Zong WK and Liu ZY: Promotion of tumor cell metastasis and vasculogenic mimicry by way of transcription coactivation by Bcl-2 and Twist1: a study of hepatocellular carcinoma. Hepatology 54: 1690-1706, 2011.

18. Che N, Zhao XL, Sun T, Zhao XM, Gu Q, Dong XY, Zhao N, Liu YR, Yao Z and Sun BC: The role of Twistl in hepatocellular carcinoma angiogenesis: a clinical study. Hum Pathol 42: 840-847, 2011.

19. Liu T, Sun B, Zhao X, Gu Q, Dong X, Yao Z, Zhao N, Chi J, Liu N, Sun R and Ma Y: HER2/neu expression correlates with vasculogenic mimicry in invasive breast carcinoma. J Cell Mol Med 17: 116-122, 2013.

20. Liu TJ, Sun BC, Zhao XL, Zhao XM, Sun T, Gu Q, Yao Z, Dong XY, Zhao N and Liu N: CD133+ cells with cancer stem cell characteristics associates with vasculogenic mimicry in triplenegative breast cancer. Oncogene 32: 544-553, 2013.

21. Sun D, Sun B, Liu T, Zhao X, Che N, Gu Q, Dong X, Yao Z, Li R, Li J, Chi J and Sun R: Slug promoted vasculogenic mimicry in hepatocellular carcinoma. J Cell Mol Med 17: 1038-1047, 2013.

22. Kurrey NK, Jalgaonkar SP, Joglekar AV, Ghanate AD, Chaskar PD, Doiphode RY and Bapat SA: Snail and Slug mediate radioresistance and chemoresistance by antagonizing p53-mediated apoptosis and acquiring a stem-like phenotype in ovarian cancer cells. Stem Cells 27: 2059-2068, 2009.

23. Nassour M, Idoux-Gillet Y, Selmi A, Côme C, Faraldo ML, Deugnier MA and Savagner P: Slug controls stem/progenitor cell growth dynamics during mammary gland morphogenesis. PLoS One 7: e53498, 2012

24. Guo W, Keckesova Z, Donaher JL, Shibue T, Tischler V, Reinhardt F, Itzkovitz S, Noske A, Zürrer-Härdi U, Bell G, Tam WL, Mani SA, van Oudenaarden A and Weinberg RA: Slug and Sox 9 cooperatively determine the mammary stem cell state. Cell 148: 1015-1028, 2012.

25. Shih JY and Yang PC: The EMT regulator Slug and lung carcinogenesis. Carcinogenesis 32: 1299-1304, 2011.

26. Basu-Roy U, Seo E, Ramanathapuram L, Rapp TB, Perry JA, Orkin SH, Mansukhani A and Basilico C: Sox 2 maintains self renewal of tumor-initiating cells in osteosarcomas. Oncogene 31: 2270-2282, 2012.

27. Leis O, Eguiara A, Lopez-Arribillaga E, Alberdi MJ, HernandezGarcia S, Elorriaga K, Pandiella A, Rezola R and Martin AG: Sox 2 expression in breast tumours and activation in breast cancer stem cells. Oncogene 31: 1354-1365, 2012.

28. Ichida JK, Blanchard J, Lam K, Son EY, Chung JE, Egli D, Loh KM, Carter AC, Di Giorgio FP, Koszka K, Huangfu D, Akutsu H, Liu DR, Rubin LL and Eggan K: A small-molecule inhibitor of tgf-Beta signaling replaces sox 2 in reprogramming by inducing nanog. Cell Stem Cell 5: 491-503, 2009.

29. Grad I, Hibaoui Y, Jaconi M, Chicha L, Bergström-Tengzelius R, Sailani MR, Pelte MF, Dahoun S, Mitsiadis TA, Töhönen V, Bouillaguet S, Antonarakis SE, Kere J, Zucchelli M, Hovatta O and Feki A: NANOG priming before full reprogramming may generate germ cell tumours. Eur Cell Mater 22: 258-274, 2011. 